\title{
Optimization of AZO films prepared on flexible substrates
}

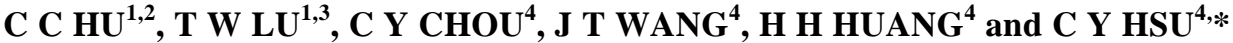 \\ ${ }^{1}$ Institute of Biomedical Engineering, National Taiwan University, Taipei, Taiwan \\ ${ }^{2}$ Department of Mechanical Engineering, Ming Chi University of Technology, Taipei, Taiwan \\ ${ }^{3}$ Department of Orthopaedic Surgery, School of Medicine, National Taiwan University, Taipei, Taiwan \\ ${ }^{4}$ Department of Mechanical Engineering, Lunghwa University of Science and Technology, Taoyuan, Taiwan
}

MS received 10 April 2013; revised 26 July 2013

\begin{abstract}
Transparent conductive $\mathrm{Al}_{2} \mathrm{O}_{3}$-doped zinc oxide (in $\mathrm{AZO}, \mathrm{Al}_{2} \mathrm{O}_{3}$ content is $\sim 2 \mathrm{wt} \%$ ) thin films are deposited on flexible polyethylene terephthalate (PET) substrates, using radio frequency (rf) magnetron sputtering. The Taguchi method with an $L_{9}\left(3^{4}\right)$ orthogonal array, a signal-to-noise ratio and analysis of variance (ANOVA) was used to determine the performance characteristics of the coating operations. Using grey relational analysis, the optimization of these deposition process parameters for AZO thin films with multiple characteristics was performed. The electrical resistivity of AZO/PET films is reduced from $2.6 \times 10^{-2}$ to $5.5 \times 10^{-3} \Omega-\mathrm{cm}$ and the visible range transmittance is $>83 \%$, using the grey relational analysis. ANOVA results for the grey relational grade indicate that $\mathrm{rf}$ power and working pressure are the two most influential factors. The effect of the rf power (in the range from 30 to $70 \mathrm{~W}$ ) and the argon working pressure (in the range from 0.90 to $1.1 \mathrm{~Pa}$ ) on the morphology and optoelectronic performance of AZO films are also investigated. An analysis of the influence of the dominant parameters in the optimal design region is helpful for adjustment of the coating parameters.
\end{abstract}

Keywords. Flexible substrates; $\mathrm{Al}_{2} \mathrm{O}_{3}$-doped zinc oxide; magnetron sputtering; grey relational analysis.

\section{Introduction}

Transparent conductive oxide films have attractive opticalelectrical characteristics, such as visible transmittance $>80 \%$ and a resistivity $<10^{-3} \Omega$-cm. They are extensively used in various transparent optoelectronic devices (LED, OLED, PLED, LCD, PDP or solar cells) (Jin et al 2000), piezoelectric devices and surface acoustic wave devices (Kassis and Saad 2003). Indium tin oxide $\left(\mathrm{In}_{2} \mathrm{O}_{3}\right.$ : $\mathrm{Sn}$, ITO), tin oxide $\left(\mathrm{SnO}_{2}\right)$ and zinc oxide $(\mathrm{ZnO})$ are the best-known materials for typical transparent conductive films. The optical transmittance of ITO films of thickness between 1000 and $1500 \AA$ can be $>90 \%$, but their targets are expensive and toxic. $\mathrm{ZnO}$ and $\mathrm{SnO}_{2}$ films are of interest because of their low cost and high crystallinity (Miyazaki et al 1997). Compared with $\mathrm{SnO}_{2}$ films, $\mathrm{ZnO}$ films are more easily etched to form fine electrodes. With the properties of low carrier concentration and high resistivity, non-doped $\mathrm{ZnO}$ films are usually used in piezoelectric applications. In order to improve the conductivity of $\mathrm{ZnO}$ films, $\mathrm{Al}, \mathrm{Ga}$ and In have been found to be effective dopants for carrier generation (Agashe et al 2004; Kao et al 2010). Of these, impuritydoped zinc oxide films, Al-doped zinc oxide (AZO) thin

\footnotetext{
*Author for correspondence (cyhsu@mail.lhu.edu.tw)
}

film has excellent characteristics (Lin et al 2009). Several deposition techniques have been used to fabricate AZO films, such as sol-gel techniques, spray pyrolysis (Paraguay et al 2000), chemical vapour deposition, pulsed laser deposition and magnetron sputtering (Szyszka 1999; Yu et al 2005a, b; Chen and Hsu 2008). The sputtering processes are the most common techniques for preparation of AZO films, because of good surface roughness, low cost and low working temperatures.

Transparent conductive oxide thin films are deposited on glass substrates for high transparency and conductivity (Moon et al 2007; Rim et al 2008). However, glass is too heavy, fragile and brittle for manufacturing. Flexible polymer substrates are remarkably flexible, lightweight and easy to handle. Recently, they are used in electronic devices, such as flat panel display devices. AZO $\left(\mathrm{Al}_{2} \mathrm{O}_{3}\right.$ content is about $2 \mathrm{wt} \%$ (Chung et al 2005) films prepared on flexible polyethylene terephthalate (PET) substrates using radio frequency (rf $13.56 \mathrm{MHz}$ ) magnetron sputtering are reported in this study. The transparent conductive AZO thin films are deposited on PET, which gives high visible transparency and high conductivity. A lower working temperature is necessary because the organic material, PET, has poor thermal stability (Fortunato et al 2003).

In the literature, many deposition factors such as power mode, rf power, total gas working pressure, oxygen ratio, 
Table 1. Deposition conditions and settings for control factors.

\begin{tabular}{|c|c|c|c|c|}
\hline \multirow{6}{*}{\multicolumn{2}{|c|}{$\begin{array}{l}\text { Substrate } \\
\text { Target } \\
\text { Gas } \\
\text { Base pressure } \\
\text { Substrate-to-target distance } \\
\text { Substrate rotate speed }\end{array}$}} & \\
\hline & & & & \\
\hline & & \multicolumn{3}{|c|}{$\begin{array}{l}\text { AZO }\left(\mathrm{ZnO}: \mathrm{Al}_{2} \mathrm{O}_{3}, 98: 2 \mathrm{wt} \%, 99.995 \% \text { pure }\right) \\
\text { Argon (99.995\% purity) }\end{array}$} \\
\hline & & \multicolumn{3}{|l|}{$5.3 \times 10^{-4} \mathrm{~Pa}$} \\
\hline & & \multicolumn{3}{|l|}{$90 \mathrm{~mm}$} \\
\hline & & \multicolumn{3}{|l|}{$20 \mathrm{rpm}$} \\
\hline Symbol & Control factor & Level 1 & Level 2 & Level 3 \\
\hline $\bar{A}$ & rf power (W) & 50 & 85 & 120 \\
\hline B & Working pressure $(\mathrm{Pa})$ & $0 \cdot 8$ & 1 & $1 \cdot 2$ \\
\hline $\mathrm{C}$ & Substrate temperature $\left({ }^{\circ} \mathrm{C}\right)$ & room & 90 & 150 \\
\hline $\mathrm{D}$ & Deposition time (min) & 20 & 35 & 50 \\
\hline
\end{tabular}

bias voltage, annealing temperature and plasma treatment deposition time (Pei et al 2006; Fernández et al 2009; Tseng et al 2011) influence the properties using rf magnetron sputtering to prepare transparent conductive AZO thin films on flexible PET substrates. Among these factors, the rf power, working pressure, substrate temperature and deposition time have most significant effects on the performance of deposition rate, resistivity and transmittance (Lin et al 2009; Tseng et al 2011).

A grey-Taguchi analysis has been successfully used to optimize the coating parameters for multiple characteristics using a Taguchi experimental design, signal-to-noise $(\mathrm{S} / \mathrm{N})$ ratio, analysis of variance (ANOVA) and grey relational analysis (Chen and Hsu 2008; Hsu and Tsang 2008). However, effect of the dominant parameters in the optimal design region is seldom discussed. In this paper, an $L_{9}\left(3^{4}\right)$ orthogonal array with four columns (including $\mathrm{rf}$ power, working pressure, substrate temperature and deposition time) and nine rows are used. The influence of the dominant parameters on the performance of the optimal design using grey-Taguchi analysis are studied. The effects of AZO films on structural, electrical and optical properties are also investigated.

\section{Experimental}

AZO transparent conducting films were deposited on PET (T60 with an area of $25 \times 25 \mathrm{~mm}$ and a thickness of $1 \mathrm{~mm}$ ) substrates, using rf magnetron sputtering with a base pressure of $5.3 \times 10^{-4} \mathrm{~Pa}$. AZO $\left(\mathrm{ZnO}: \mathrm{Al}_{2} \mathrm{O}_{3}, 98\right.$ : 2 wt\%, 99.995\% pure) was a commercially available hot-pressed and sintered target, with a diameter of 2 in and a thickness of 0.25 in. All of PET substrates were ultrasonically cleaned in acetone, rinsed with deionized water and dried in nitrogen. The substrate-to-target distance was $90 \mathrm{~mm}$ and the rotational speed of the substrate was maintained at $20 \mathrm{rpm}$, in order to ensure good surface morphology. The deposition conditions and the settings for the control factors are shown in table 1 . Before deposition, the target was pre-sputtered at a constant rf power of $20 \mathrm{~W}$ for $10 \mathrm{~min}$ to remove any contamination.
After deposition, the electrical resistivity was measured by the four-point probe method (Mitsubishi chemical MCP-T600). The optical transmittance measurement was performed using a UV-Vis spectrophotometer in the wavelength range of $300-800 \mathrm{~nm}$. The film thickness was measured using a surface profilometer ( $\alpha$-step, AMBIOS XP-1). A field emission scanning electron microscope (SEM, JEOL, JSM-6500F) was used to analyse the surface morphologies and an atomic force microscope (AFM, PSIA-XE-100) provided topographic images. The structural properties were determined using X-ray diffraction (XRD, Rigaku-2000 X-ray generator), using $\mathrm{CuK} \alpha$ radiation $(\lambda=1.54056 \AA)$ with an angle incidence of $1^{\circ}$. The grain sizes of the films were calculated from XRD data, using the Debye-Scherrer formula.

\section{Grey relational analysis and optimization}

Grey relational analysis is a method for analysing the relationship between sequences using less data with multiple factors and is considered helpful to statistical regression analysis. Based on the grey system theory, the grey relational analysis can be used to solve complicated interdependence of parameters among multiple performance characteristics effectively (Deng 1989; Kuo et al 1998; Tarng et al 2002; Chen and Hsu 2008; Hsu and Tsang 2008). In this paper, a Taguchi experimental design and grey relational analysis were used to clarify the effect of various sputtering factors, in order to obtain low resistivity, good visible transparency and a high deposition rate, i.e. to optimize the design of the process for the deposition of the transparent conductive AZO thin film.

Taguchi approach is a powerful design tool for highquality systems (Phillip 1989). To conduct the Taguchi method efficiently, an orthogonal array is employed for the design of experiments. The number of experiments, $N_{\text {Taguchi }}$, is calculated as follows

$$
N_{\text {Taguchi }}=1+\sum_{i=1}^{N_{\mathrm{p}}}\left(L_{i}-1\right),
$$

where $N_{\mathrm{p}}$ is the number of parameters and $L_{i}$ is the number of levels. In this study, there are 4 parameters and 
3 levels; therefore, the number of experiments are $1+4 *(3-1)$, i.e. nine experiments.

\subsection{Analysis of $S / N$ ratio}

In order to quantify the variation in the experiments, generically different signal-to-noise $(S / N)$ ratios were employed, depending on the particular type of characteristics involved. These included 'lower is better' (LB), 'nominal is best' (NB) and 'higher is better' (HB). $S / N$ ratios were calculated using the following equations

$$
\begin{aligned}
& \eta=10 \log (S / N \text { ratio })=10 \log \frac{1}{\sigma^{2}}=-10 \log \sigma^{2}, \\
& \text { HB: } \sigma^{2}=\frac{1}{n}\left(\frac{1}{y_{1}^{2}}+\frac{1}{y_{2}^{2}}+\cdots+\frac{1}{y_{n}^{2}}\right),
\end{aligned}
$$

$$
\text { LB: } \mathrm{LB}: \sigma^{2}=\frac{1}{n}\left(y_{1}^{2}+y_{2}^{2}+\cdots \cdots+y_{n}^{2}\right),
$$

where $\eta$ denotes the calculated value of $S / N$ ratio (unit: $\mathrm{d} B) \cdot y_{n}$ represents the measured experimental value and $n$ is a repeated number. A larger set of $y_{n}$ squares in the HB (3) induces a small value for $\sigma^{2}$ and a large $S / N$ ratio value $\eta$, in (2). Good visible transmittance and deposition rate are in the category of higher-the-better performance characteristics and electrical resistivity is lower the better. The mean $S / N$ ratio for each level of the process parameters is summarized in the $S / N$ response table.

\subsection{Analysis of variance}

An ANOVA and the $F$-test are used to analyse the experimental data as follows

$$
S_{\mathrm{m}}=\frac{\left(\sum \eta_{i}\right)^{2}}{9}, S_{\mathrm{m}}=\sum \eta_{i}^{2}-S_{\mathrm{m}} \text {, }
$$

$$
\begin{aligned}
& S_{A}=\frac{\left(\sum \eta_{A i}^{2}\right)^{2}}{N}-S_{\mathrm{m}}, S_{\mathrm{E}}=S_{\mathrm{T}}-\sum S_{A}, \\
& V_{A}=\frac{S_{A}}{f_{A}}, \quad F_{A 0}=\frac{V_{A}}{V_{\mathrm{E}}},
\end{aligned}
$$

where $\eta_{i}$ is the $\eta$ value for each experiment ( $i=1-9$ ), $S_{\mathrm{m}}$ is the square of the sum due to the means and $S_{\mathrm{T}}$ is the sum of the squares due to the total variation. $S_{A}$ is the sum of the squares due to parameter $A, \eta_{A i}$ is the sum of the $i$ th level of parameter $A(i=1,2,3), N$ is the repeating number of each level of parameter, $A$ and $S_{\mathrm{E}}$ is the sum of the squares due to error. The values, $f_{A}, V_{A}, V_{\mathrm{E}}$ and $F_{A 0}$, are the degree of freedom, the variance and the $F$-test value for parameter, $A$, respectively.

\subsection{Grey relational analysis}

Grey relational analysis was used to determine the complicated relationships between the multiple performance characteristics for AZO/PET deposition. The grey relational coefficient is

$$
\begin{aligned}
& r\left(x_{0}(k), x_{i}(k)\right) \\
& =\frac{\min _{i} \min _{k}\left|x_{0}(k)-x_{i}(k)\right|+\xi \max _{i} \max _{k}\left|x_{0}(k)-x_{i}(k)\right|}{\left|x_{0}(k)-x_{i}(k)\right|+\xi \max _{i} \max _{k}\left|x_{0}(k)-x_{i}(k)\right|},
\end{aligned}
$$

where $x_{i}(k)$ is the normalized value of the $k$ th performance characteristic in the $i$ th experiment and $\xi$ is the coefficient adjusted between 0 and 1 , according to the actual system requirements. In this paper, $\xi=0.5$, because all of

\begin{tabular}{|c|c|c|c|c|c|c|c|c|c|c|c|c|c|}
\hline \multirow[b]{2}{*}{ Exp. } & \multicolumn{4}{|c|}{ Factors } & \multicolumn{2}{|c|}{$\begin{array}{l}\text { Deposition } \\
\text { rate }(\mathrm{nm} / \mathrm{min})\end{array}$} & \multirow[b]{2}{*}{$S / N(\mathrm{~dB})$} & \multicolumn{2}{|c|}{$\begin{array}{c}\text { Resistivity } \\
\left(10^{-3} \Omega \text {-cm }\right)\end{array}$} & \multirow[b]{2}{*}{$S / N(\mathrm{~dB})$} & \multicolumn{2}{|c|}{$\begin{array}{c}\text { Transmittance } \\
\text { (\%) }\end{array}$} & \multirow[b]{2}{*}{$S / N(\mathrm{~dB})$} \\
\hline & A & B & C & $\mathrm{D}$ & $D P_{1}$ & $D P_{2}$ & & $R_{1}$ & $R_{2}$ & & $T_{1}$ & $T_{2}$ & \\
\hline 1 & 1 & 1 & 1 & 1 & $4 \cdot 1$ & $4 \cdot 2$ & $12 \cdot 36$ & $22 \cdot 2$ & $21 \cdot 9$ & $-26 \cdot 87$ & $77 \cdot 3$ & $75 \cdot 6$ & $37 \cdot 67$ \\
\hline 2 & 1 & 2 & 2 & 2 & $4 \cdot 2$ & $4 \cdot 2$ & $12 \cdot 47$ & $26 \cdot 6$ & $25 \cdot 8$ & $-28 \cdot 37$ & $88 \cdot 6$ & $85 \cdot 4$ & 38.79 \\
\hline 3 & 1 & 3 & 3 & 3 & $5 \cdot 0$ & $5 \cdot 2$ & $14 \cdot 15$ & $5 \cdot 73$ & $5 \cdot 65$ & $-15 \cdot 10$ & $79 \cdot 9$ & $80 \cdot 2$ & 38.07 \\
\hline 4 & 2 & 1 & 2 & 3 & $7 \cdot 5$ & $7 \cdot 5$ & $17 \cdot 50$ & $27 \cdot 3$ & $27 \cdot 8$ & $-28 \cdot 80$ & $74 \cdot 1$ & $72 \cdot 8$ & $37 \cdot 32$ \\
\hline 5 & 2 & 2 & 3 & 1 & $6 \cdot 2$ & $6 \cdot 5$ & $16 \cdot 05$ & $37 \cdot 4$ & $36 \cdot 9$ & $-31 \cdot 40$ & $81 \cdot 9$ & $80 \cdot 6$ & $38 \cdot 20$ \\
\hline 6 & 2 & 3 & 1 & 2 & $7 \cdot 5$ & $7 \cdot 7$ & $17 \cdot 61$ & $34 \cdot 4$ & $33 \cdot 8$ & $-30 \cdot 66$ & $79 \cdot 0$ & $77 \cdot 4$ & $37 \cdot 86$ \\
\hline 7 & 3 & 1 & 3 & 2 & $11 \cdot 7$ & $12 \cdot 2$ & $21 \cdot 54$ & $96 \cdot 6$ & $95 \cdot 4$ & $-39 \cdot 65$ & $78 \cdot 8$ & $77 \cdot 6$ & $37 \cdot 86$ \\
\hline 8 & 3 & 2 & 1 & 3 & $10 \cdot 3$ & $11 \cdot 3$ & $20 \cdot 64$ & $24 \cdot 7$ & $23 \cdot 5$ & $-27 \cdot 64$ & $76 \cdot 7$ & $75 \cdot 6$ & 37.63 \\
\hline 9 & 3 & 3 & 2 & 1 & $10 \cdot 0$ & $10 \cdot 4$ & $20 \cdot 17$ & $46 \cdot 2$ & $45 \cdot 1$ & $-33 \cdot 19$ & $74 \cdot 5$ & $73 \cdot 8$ & $37 \cdot 40$ \\
\hline
\end{tabular}
the parameters are equally weighted. The grey relational grade, defined as follows, is a weighing-sum of the grey relational coefficient

$$
r\left(x_{0}, x_{i}\right)=\frac{1}{N} \sum_{k=1}^{N} r\left(x_{0}(k), x_{i}(k)\right),
$$

Table 2. Experimental results and $S / N$ ratios for deposition rate, resistivity and transmittance of the AZO/PET (the experiments were repeated twice). 
Table 3. ANOVA results for AZO/PET deposition rate, resistivity and transmittance.

\begin{tabular}{|c|c|c|c|c|c|c|c|}
\hline \multirow[b]{2}{*}{ Factors } & \multicolumn{3}{|c|}{$S / N$ ratio $(\mathrm{dB})$} & \multirow{2}{*}{$\begin{array}{l}\text { Degree of } \\
\text { freedom }\end{array}$} & \multirow{2}{*}{$\begin{array}{l}\text { Sum of } \\
\text { square }\end{array}$} & \multirow[b]{2}{*}{ Variance } & \multirow{2}{*}{$\begin{array}{c}\text { Contribution } \\
\qquad(P \%)\end{array}$} \\
\hline & Level 1 & Level 2 & Level 3 & & & & \\
\hline \multicolumn{8}{|c|}{ Deposition rate } \\
\hline A & $12 \cdot 99$ & $17 \cdot 06$ & $20 \cdot 80$ & 2 & $91 \cdot 40$ & $45 \cdot 70$ & $95 \cdot 29$ \\
\hline B & $17 \cdot 14$ & $16 \cdot 40$ & $17 \cdot 31$ & 2 & 1.42 & $0 \cdot 71$ & $1 \cdot 48$ \\
\hline $\mathrm{C}$ & $16 \cdot 88$ & $16 \cdot 71$ & $17 \cdot 25$ & 2 & 0.46 & 0.23 & 0.48 \\
\hline $\mathrm{D}$ & $16 \cdot 20$ & $17 \cdot 21$ & $17 \cdot 44$ & 2 & $2 \cdot 63$ & $1 \cdot 32$ & $2 \cdot 75$ \\
\hline Total & & & & 8 & $95 \cdot 90$ & & 100 \\
\hline \multicolumn{8}{|c|}{ Electrical resistivity } \\
\hline A & $-23 \cdot 45$ & $-30 \cdot 29$ & $-33 \cdot 49$ & 2 & $158 \cdot 01$ & $79 \cdot 00$ & $46 \cdot 56$ \\
\hline B & $-31 \cdot 77$ & $-29 \cdot 14$ & $-26 \cdot 32$ & 2 & $44 \cdot 68$ & $22 \cdot 34$ & $13 \cdot 17$ \\
\hline $\mathrm{C}$ & $-28 \cdot 39$ & $-30 \cdot 12$ & $-28 \cdot 72$ & 2 & $5 \cdot 07$ & $2 \cdot 54$ & $1 \cdot 50$ \\
\hline $\mathrm{D}$ & $-30 \cdot 49$ & $-32 \cdot 89$ & $-23 \cdot 85$ & 2 & $131 \cdot 54$ & $65 \cdot 77$ & $38 \cdot 77$ \\
\hline Total & & & & 8 & $339 \cdot 30$ & & 100 \\
\hline \multicolumn{8}{|c|}{ Visible range transmittance } \\
\hline A & $38 \cdot 17$ & $37 \cdot 79$ & $37 \cdot 63$ & 2 & 0.46 & $0 \cdot 23$ & $28 \cdot 57$ \\
\hline B & $37 \cdot 62$ & $38 \cdot 20$ & $37 \cdot 78$ & 2 & $0 \cdot 56$ & $0 \cdot 28$ & $34 \cdot 78$ \\
\hline $\mathrm{C}$ & $37 \cdot 72$ & $37 \cdot 84$ & $38 \cdot 04$ & 2 & $0 \cdot 16$ & $0 \cdot 08$ & $9 \cdot 94$ \\
\hline $\mathrm{D}$ & $37 \cdot 75$ & $38 \cdot 17$ & $37 \cdot 67$ & 2 & 0.43 & $0 \cdot 22$ & $26 \cdot 71$ \\
\hline Total & & & & 8 & $1 \cdot 61$ & & 100 \\
\hline
\end{tabular}

where $N$ is the number of performance characteristics. The grey relational grade shows the correlation between the reference sequence and the comparability sequence. The evaluated grey relational grade fluctuates from 0 to 1 . It equals 1 if these two sequences are identically coincident. The optimal combination of AZO/PET deposition parameters is obtained from grey relational analysis and a statistical analysis of variance.

\section{Results and discussion}

Table 2 shows the experimental results for AZO/PET sputtering process, with regard to deposition rate, resistivity and transmittance and the corresponding $S / N$ ratios. ANOVA results, including $S / N$ ratio, degree of freedom (DOF), sum of square, variance and contribution are presented in table 3. DOF of a specific parameter is calculated as the number of experimental levels - 1 (Osama et al 2009). In this study, the levels of the 4 factors are all set as 3. Therefore, the individual DOF of any factor is 2, and the total DOF of one set of the experiment is $4 *(3-1)$, i.e. 8 DOF. It is seen that that the rf power has the dominant effect on the deposition rate, with a contribution ratio of almost $95 \cdot 29 \%$. The deposition rate is increased when the rf power is increased. These higher-energy particles have high surface mobility and therefore more growth takes place at the surface (Yu et al 2005a, b). The contribution ratios of working pressure, substrate temperature and deposition time to deposition rate are only $1.48,0.48$ and $2 \cdot 70 \%$, respectively. These shows that the deposition rate can only fluctuate within a small range, according to these control factors.
Table 4. Grey relational grade and its order for each deposition level.

\begin{tabular}{lcc}
\hline Exp. & Grey relational grade & Rank \\
\hline 1 & $0 \cdot 5625$ & 4 \\
2 & 0.8438 & 1 \\
3 & $0 \cdot 7468$ & 2 \\
4 & $0 \cdot 5035$ & 7 \\
5 & $0 \cdot 5651$ & 3 \\
6 & $0 \cdot 5244$ & 6 \\
7 & 0.3842 & 9 \\
8 & 0.5474 & 5 \\
9 & 0.4379 & 8 \\
\hline
\end{tabular}

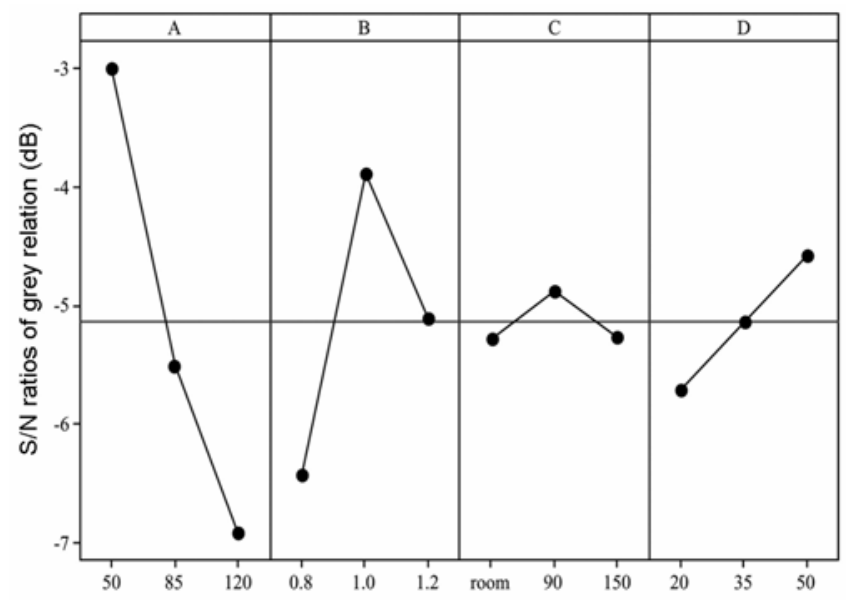

Figure 1. $S / N$ response graph for the grey relational grade for AZO/PET deposition process. Note: A = rf power (W), $\mathrm{B}=$ working pressure $(\mathrm{Pa}), \mathrm{C}=$ substrate temperature $\left({ }^{\circ} \mathrm{C}\right)$, $\mathrm{D}=$ deposition time $(\mathrm{min})$. 
Table 5. Confirmation test for resistivity and transmittance, using the grey theory prediction design and the orthogonal array parameters.

\begin{tabular}{lccc}
\hline & $\begin{array}{c}\text { Orthogonal array } \\
\text { parameter } \mathrm{A}_{1} \mathrm{~B}_{2} \mathrm{C}_{2} \mathrm{D}_{2}\end{array}$ & $\begin{array}{c}\text { Grey theory prediction } \\
\text { design } \mathrm{A}_{1} \mathrm{~B}_{2} \mathrm{C}_{2} \mathrm{D}_{3}\end{array}$ & $\begin{array}{c}\text { Improvement } \\
\text { rate (\%) }\end{array}$ \\
\hline Resistivity $\left(10^{-3} \Omega-\mathrm{cm}\right)$ & 26 & $5 \cdot 5$ & $78 \cdot 84$ \\
Transmittance $(\%)$ & $87 \cdot 6$ & $83 \cdot 0$ & $-5 \cdot 25$ \\
\hline
\end{tabular}

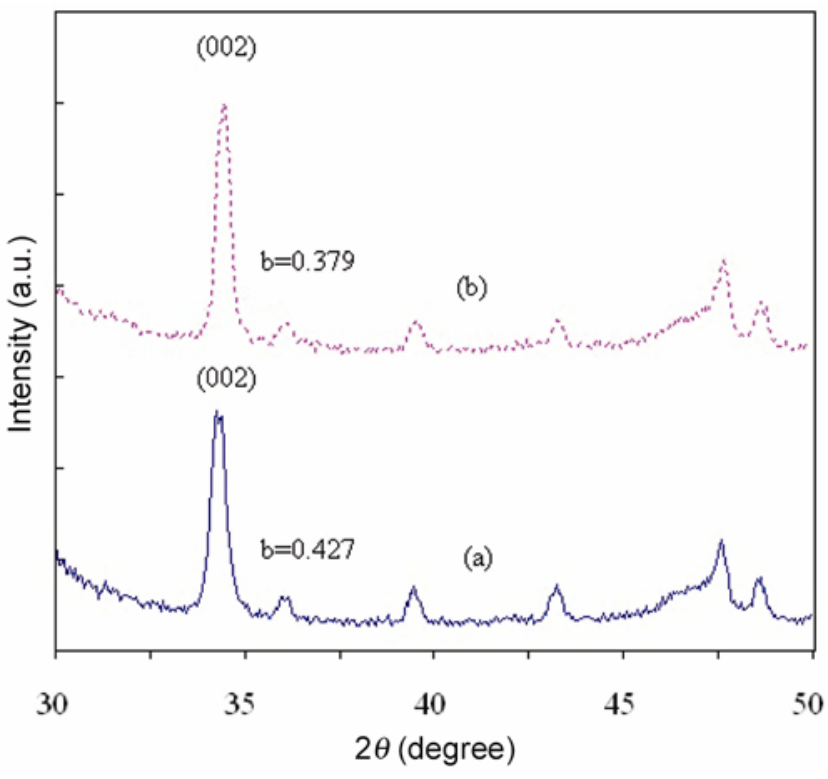

Figure 2. X-ray diffraction spectrum for AZO/PET films: (a) orthogonal array parameters and (b) grey theory prediction design (b: full-width at half-maximum FWHM).

ANOVA analysis in table 3 results show that the rf power has the dominant effect on AZO/PET electrical resistivity, with a contribution ratio of almost $46 \cdot 56 \%$, followed by deposition time with $38 \cdot 77 \%$. A lower $\mathrm{rf}$ power produces lower electrical resistivity. As the rf power increases, the electrical resistivity of AZO films increases. The increase in resistivity occurs because of the damage to AZO film caused by the collision of negative ions (Lee et al 2008). ANOVA results reveal that the working pressure dominates transmittance, with a contribution ratio of $34.78 \%$, followed by the rf power and deposition time with 28.57 and $26 \cdot 71 \%$, respectively. Suitable values for rf power $(50 \mathrm{~W})$, working pressure (1 $\mathrm{Pa})$ and deposition time (35 min) result in an increase in the transmittance of AZO films on PET.

\subsection{Optimal deposition parameters}

Using (7) and (8), the grey relational grade for each experiment and its order in the optimization process using $L_{9}$ orthogonal array are shown in table 4 . The parameter set, $\mathrm{A}_{1} \mathrm{~B}_{2} \mathrm{C}_{2} \mathrm{D}_{2}\left(50 \mathrm{~W}, 1 \mathrm{~Pa}, 90^{\circ} \mathrm{C}, 35 \mathrm{~min}\right)$, in experiment 2 has the best multiple performance (grey relational grade $0 \cdot 8438$ ) of the nine experiments. $S / N$ response graph for

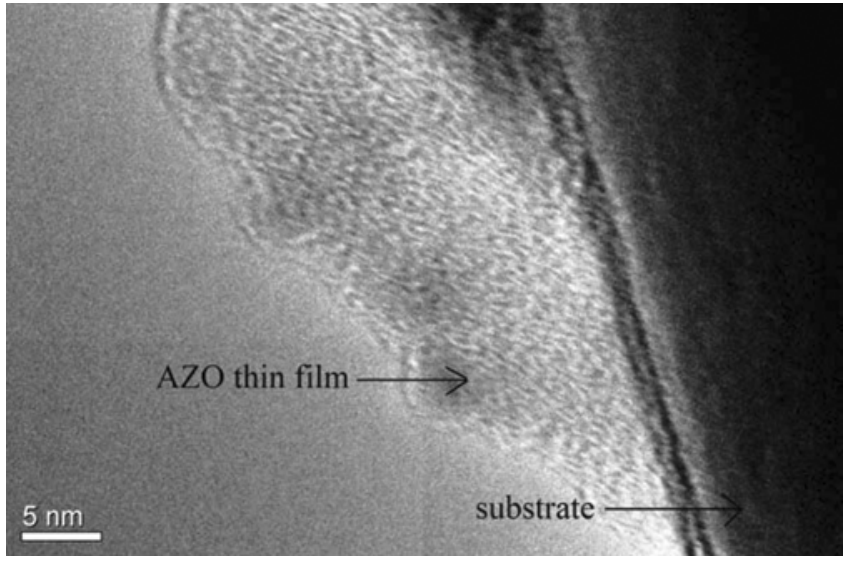

Figure 3. High-resolution TEM images of AZO thin film deposited using a grey theory prediction design.

the grey relational grade shown in figure 1 shows that better multiple qualities are obtained by using the parameter set, $\mathrm{A}_{1} \mathrm{~B}_{2} \mathrm{C}_{2} \mathrm{D}_{3}\left(50 \mathrm{~W}, 1 \mathrm{~Pa}, 90^{\circ} \mathrm{C}, 50 \mathrm{~min}\right)$. The confirmed experimental results for the multiple performance characteristics of AZO/PET thin films are shown in table 5. A comparison of the grey theory prediction design $\left(A_{1} B_{2} C_{2} D_{3}\right)$ with the orthogonal array process parameters $\left(A_{1} B_{2} C_{2} D_{2}\right)$ shows that the electrical resistivity of $\mathrm{AZO} / \mathrm{PET}$ thin films is reduced from $2.6 \times 10^{-2}$ to $5.5 \times 10^{-3} \Omega$-cm, which is an improvement of $78.84 \%$. An increase in the film thickness from 170 to $258 \mathrm{~nm}$ leads to a slight decrease in the visible range transmittance from 87.6 to $83.0 \%$ (including PET substrate).

Figure 2 shows XRD diffraction patterns for AZO films. Using grey theory prediction design, it can be seen that the intensity of the $\left(\begin{array}{lll}0 & 0 & 2\end{array}\right)$ diffraction peak becomes stronger and there is a decrease in the full width at half maximum (FWHM, reduced from 0.427 to $0 \cdot 379$ ), which leads to an improvement in the crystallinity and a larger crystallite size for the films (figure 2b). Figure 3 shows high-resolution TEM images of AZO thin film deposited using grey theory prediction design. Figure 4 shows the SEM and AFM images of the films deposited with (a) orthogonal array parameters and (b) grey theory prediction design. A larger grain size (figure 4b) reduces the grain boundary scattering and increases carrier lifetime, which leads to increased conductivity, because of the increase in carrier concentration and Hall mobility (Lv et al 

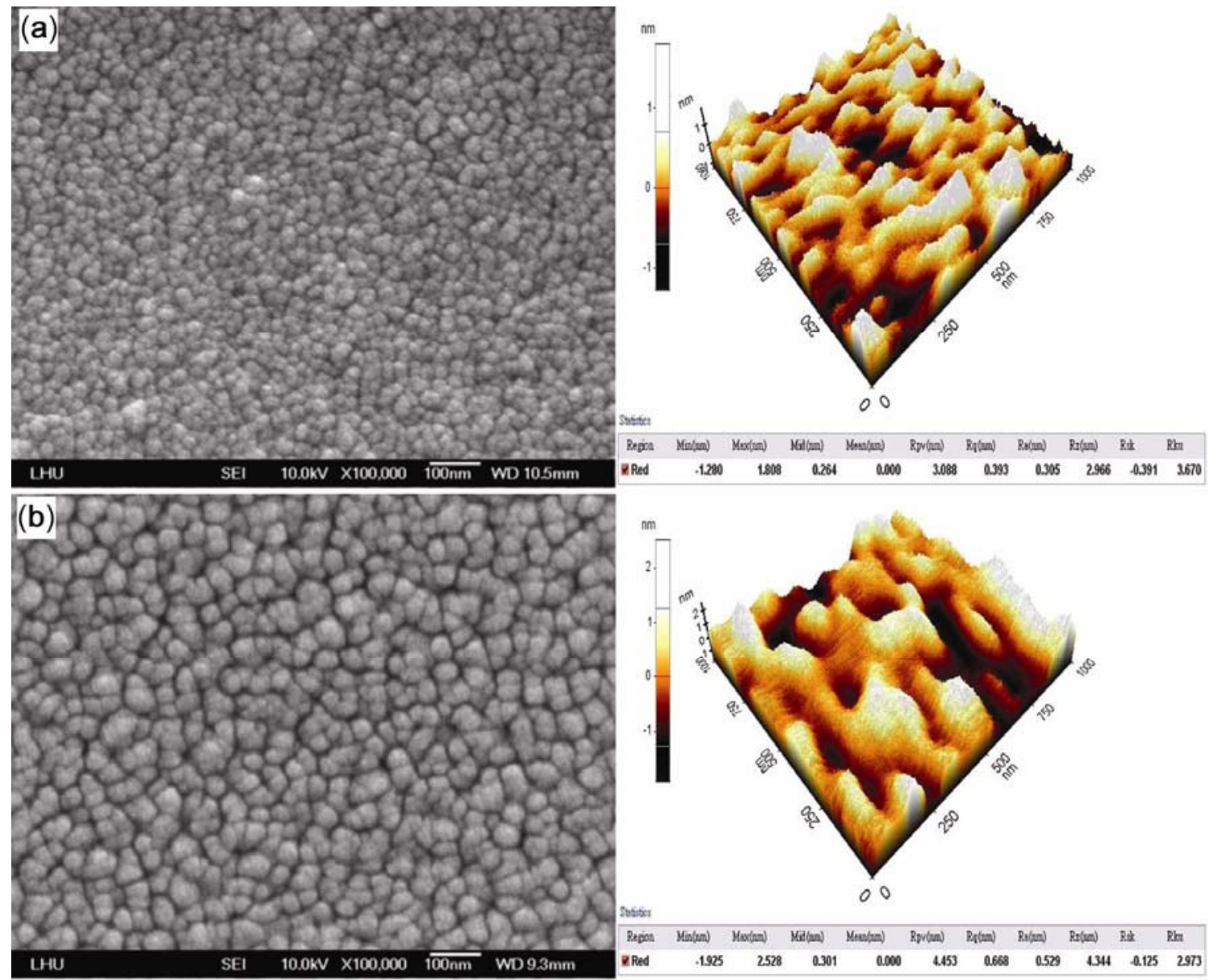

Figure 4. SEM (left) and AFM (right) images of the films corresponding to figure 2: (a) orthogonal array parameters (surface roughness of $\left.R_{\mathrm{a}}=0.305 \mathrm{~nm}\right)$ and $(\mathbf{b})$ grey theory prediction design $\left(R_{\mathrm{a}}=0.529 \mathrm{~nm}\right)$.

Table 6. Results of ANOVA for the grey relational grade in the AZO grown.

\begin{tabular}{|c|c|c|c|c|c|c|c|}
\hline \multirow[b]{2}{*}{ Factors } & \multicolumn{3}{|c|}{$S / N$ ratio $(\mathrm{dB})$} & \multirow{2}{*}{$\begin{array}{c}\text { Degree of } \\
\text { freedom }\end{array}$} & \multirow{2}{*}{$\begin{array}{l}\text { Sum of } \\
\text { square }\end{array}$} & \multirow{2}{*}{$\begin{array}{c}\text { Contribution } \\
\text { Variance }\end{array}$} & \multirow[b]{2}{*}{$(P \%)$} \\
\hline & Level 1 & Level 2 & Level 3 & & & & \\
\hline A & $-3 \cdot 003$ & $-5 \cdot 508$ & $-6 \cdot 905$ & 2 & $23 \cdot 45$ & 11.73 & $66 \cdot 35$ \\
\hline B & $-6 \cdot 422$ & $-3 \cdot 889$ & $-5 \cdot 105$ & 2 & $9 \cdot 63$ & $4 \cdot 82$ & $27 \cdot 26$ \\
\hline C & $-5 \cdot 279$ & $-4 \cdot 869$ & $-5 \cdot 267$ & 2 & $0 \cdot 33$ & $0 \cdot 17$ & 0.96 \\
\hline $\mathrm{D}$ & $-5 \cdot 709$ & $-5 \cdot 130$ & $-4 \cdot 577$ & 2 & 1.92 & $0 \cdot 96$ & $5 \cdot 43$ \\
\hline Total & & & & 8 & $35 \cdot 33$ & & 100 \\
\hline
\end{tabular}

2006). The surface roughness increases from $R_{\mathrm{a}}=0.305$ to $0.529 \mathrm{~nm}$, when grey theory prediction design is used.

\subsection{Effect of rf power and argon working pressure}

Table 6 shows the results of ANOVA for multiple performance characteristics of AZO grown. Using grey relational analysis, it can be seen that the rf power ( $P=66 \cdot 35 \%)$ strongly affects the multiple performance characteristics. In addition, working pressure also has some influence, with a contribution ratio of about $27 \cdot 26 \%$.
When the working pressure $(1 \mathrm{~Pa})$, substrate temperature $\left(90{ }^{\circ} \mathrm{C}\right)$ and deposition time (50 min) are constant, the rf power is varied between 30, 40, 50, 60 and $70 \mathrm{~W}$, respectively (table 7). Figure 5(a) shows XRD patterns for AZO films grown on PET substrates as a function of rf power. All of the films display ( $\left(\begin{array}{lll}0 & 0 & 2\end{array}\right)$ peaks, which indicate that AZO films have a hexagonal $\mathrm{ZnO}$ wurtzite structure. An increase in rf power (from 30 to $70 \mathrm{~W}$ ) produces a gradual decrease in FWHM of XRD for the AZO films. In figure 5(b), it is observed that using Taguchi experimental method the resistivity decreases when the rf power is 
Table 7. Settings for rf power and working pressure.

\begin{tabular}{ll}
\hline Substrate & $\begin{array}{c}\text { PET }(\mathrm{T} 60, \text { area } 25 \times 25 \mathrm{~mm}, \\
\text { thickness } 1 \mathrm{~mm}) \\
\text { Target }\end{array}$ \\
$\begin{array}{c}\text { AZO }\left(\mathrm{ZnO}: \mathrm{Al}_{2} \mathrm{O}_{3}, \quad 98: 2 \mathrm{wt} \%,\right. \\
\text { Argon }(99.995 \%)\end{array}$ \\
Gas & $\begin{array}{l}5 \cdot 3 \times 10^{-4} \mathrm{~Pa} \\
\text { Base pressure }\end{array}$ \\
Substrate-to-target distance & $90 \mathrm{~mm}$ \\
Substrate rotate speed & $20 \mathrm{rpm}$ \\
Substrate temperature & $90{ }^{\circ} \mathrm{C}$ \\
Deposition time & $50 \mathrm{~min}$ \\
Working pressure & $1 \mathrm{~Pa}$ \\
rf power & $30,40,50,60,70 \mathrm{~W}$ \\
rf power & $50 \mathrm{~W}$ \\
Working pressure & $0 \cdot 9,0 \cdot 95,1,1 \cdot 05,1 \cdot 1 \mathrm{~Pa}$ \\
\hline
\end{tabular}
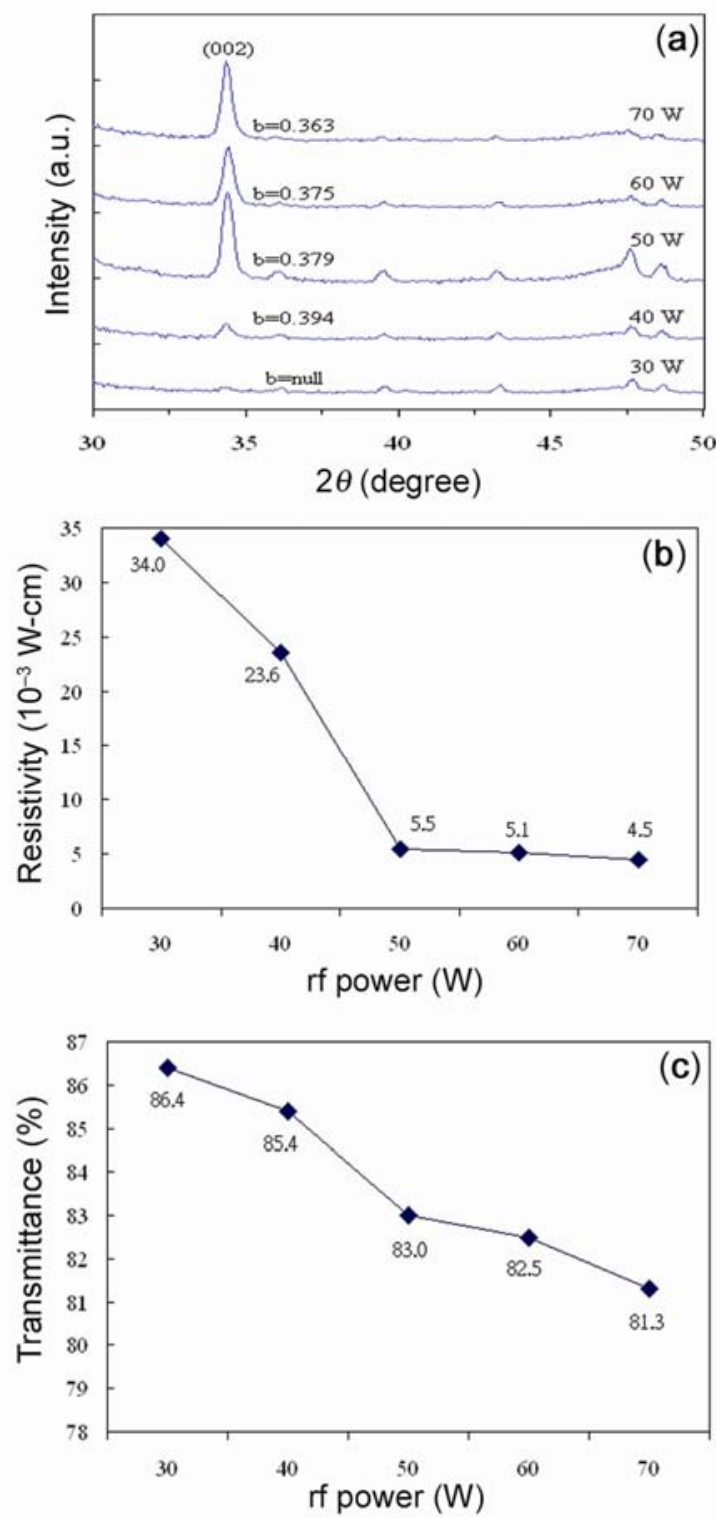

Figure 5. (a) X-ray curve, (b) electrical resistivity and (c) visible range transmittance, plotted as a function of rf power for AZO films grown on PET. increased. The lowest resistivity of $4.5 \times 10^{-3} \Omega$-cm is achieved at the highest rf power, $70 \mathrm{~W}$. If the electron concentration is enhanced, the resulting resistivity is lower. The small amounts of $\mathrm{Al}_{2} \mathrm{O}_{3}$ doped into $\mathrm{ZnO}$ matrix to form AZO target provided excess electrons. The electrical nature of AZO films was affected by the extrinsic dopants (Chen and Duh 1991). This has been attributed to the changes in the stoichiometry and/or in the crystallinity of the films with the growth rate (Jeong and
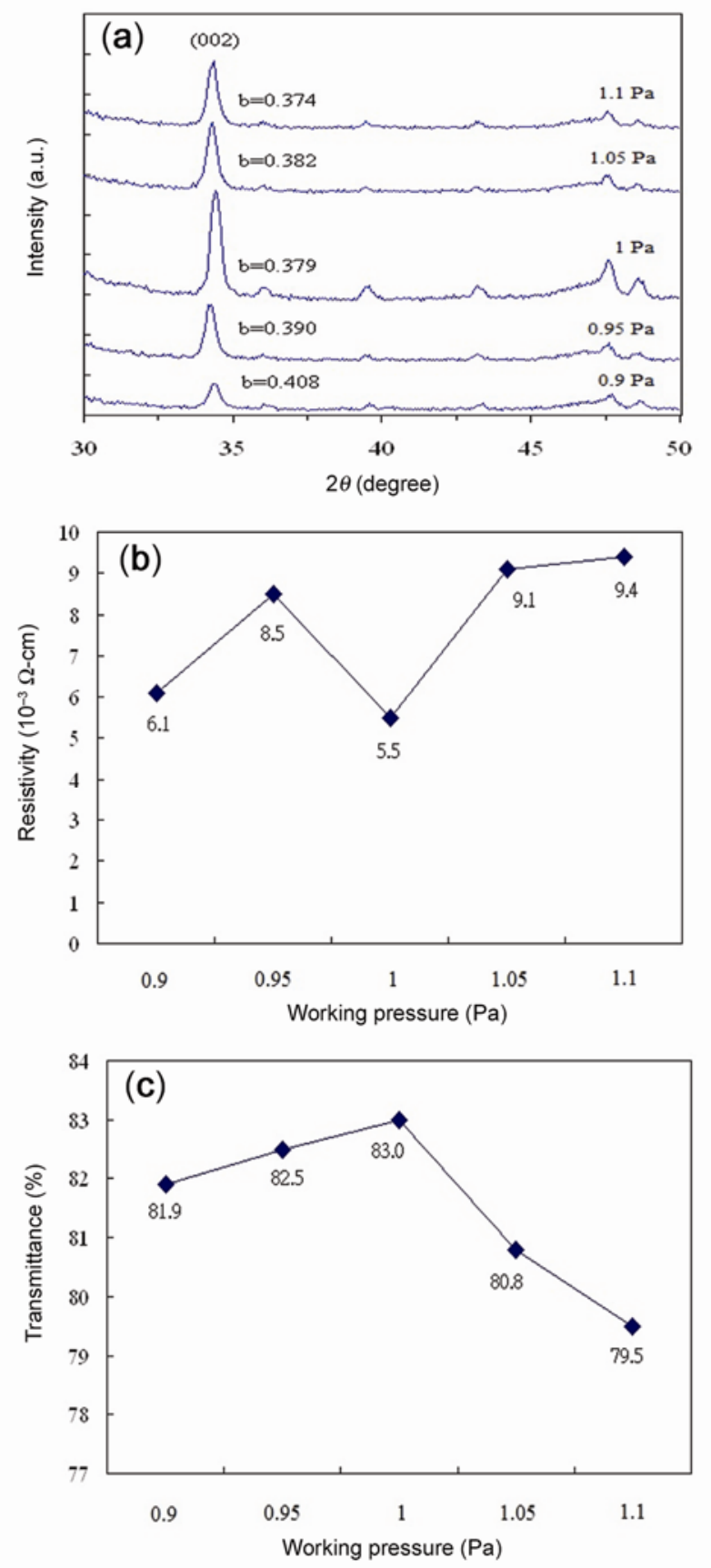

Figure 6. (a) X-ray curve, (b) electrical resistivity and (c) visible range transmittance, plotted as a function of working pressure, for AZO films grown on PET. 
Boo 2004). However, the transmission spectrum for this sample is poor, showing an average transmission in the visible range of around $81 \cdot 3 \%$ (figure $5 c$ ).

Figure 6(a) shows XRD patterns for the AZO films grown on PET substrates, as a function of working pressure. The $\left(\begin{array}{lll}0 & 0 & 2\end{array}\right)$ peak of X-ray curves is the highest at working pressure of $1 \mathrm{~Pa}$. Using ANOVA analysis in table 3, rf power has the dominant effect on the deposition rate, with a contribution ratio of almost $95 \cdot 29 \%$, but the contribution ratio of working pressure is $<1.5 \%$. This implied that the rate of deposition is the highest at working pressure of $1 \mathrm{~Pa}$ but the effect is not significant. The lowest resistivity and highest transmission are achieved at a working pressure of $1 \mathrm{~Pa}$ as well (figure 6(b) and (c)).

\section{Conclusions}

This study uses the Taguchi experimental design and grey relational analysis to clarify the influence of various process parameters on AZO/PET thin films using multiple performance characteristics. Experiments using an appropriate $L_{9}\left(3^{4}\right)$ orthogonal array and a Taguchi experimental design are conducted first. The experimental results are used to calculate the $S / N$ ratio, the grades, in order to predict the optimal parameters using grey relational analysis. The electrical resistivity of the AZO/PET films is reduced from $2.6 \times 10^{-2}$ to $5.5 \times 10^{-3} \Omega$-cm and the visible range transmittance is $>83 \%$, using the grey relational analysis. ANOVA for multiple performance characteristics shows that the rf power and working pressure have a dominant effect on AZO/PET electrical resistivity and visible transmittance, respectively. The results show that this method greatly simplifies the optimization of complicated multiple performance characteristics.

\section{References}

Agashe C, Kluth O, Hüpkes J, Zastrow U, Rech B and Wuttig M 2004 J. Appl. Phys. 951911

Chen D Y and Hsu C Y 2008 Superlattice Microst. 44742

Chen Y I and Duh J G 1991 Mater. Chem. Phys. 27427
Chung Y M, Moon C S, Jung M J and Han J G 2005 Surf. Coat. Technol. 200936

Deng J L 1989 J. Grey Syst. 11

Fernández S, Martínez-Steele A, Gandía J J and Naranjo F B 2009 Thin Solid Films 5173152

Fortunato E, Gonçalves A, Assunção V, Marques A, Águas H, Pereira L, Ferreira I and Martins R 2003 Thin Solid Films 442121

Hsu C Y and Tsang C H 2008 Sol. Energ. Mater. Sol. Cells 92 530

Jeong S H and Boo J H 2004 Thin Solid Films 105447

Jin B J, Bae S H, Lee S Y and Im S 2000 Mater. Sci. Eng. B71 301

Kao J Y, Tsao C C, Wang S S and Hsu C Y 2010 Int. J. Adv. Manuf. Technol. 47395

Kassis A and Saad M 2003 Sol. Energ. Mater. Sol. Cells 80491

Kuo H H, Wu J H and Chin J 1998 J. Grey Syst. 147

Lee J, Jung H, Lee J, Lim D, Yang K, Yi J and Song W C 2008 Thin Solid Films 5161634

Lin Y C, Chen M Z, Kuo C C and Yen W T 2009 Colloids Surf. A: Physicochem. Eng. Aspects 33752

Lv M, Xiu X, Pang Z, Dai Y and Han S 2006 Appl. Surf. Sci. 2525687

Miyazaki M, Sato K, Mitsui A and Nishimura H 1997 J. Non-Cryst. Solids 218323

Moon C S, Chung Y M, Jung W S and Han J G 2007 Surf. Coat. Technol. 2105035

Osama S M, Haitham R S and Hussam L A 2009 Eng. Tech. J. 271143

Paraguay D F, Morales J, Estrada L W, Andrade E and MikiYoshida M 2000 Thin Solid Films 36616

Pei Z L, Zhang X B, Zhang G P, Gong J, Sun C, Huang R F and Wen L S 2006 Thin Solid Films 49720

Phillip J R 1989 Taguchi techniques for quality engineering (New York: McGraw-Hill)

Rim Y S, Kim S M, Choi H W, Park S J and Kim K H 2008 Colloid. Surf. A313 461

Szyszka B 1999 Thin Solid Films 351164

Tarng Y S, Juang S C and Chang C H 2002 J. Mater. Process Technol. 1281

Tseng C H, Huang C H, Chang H C, Chen D Y, Chou C P and Hsu C Y 2011 Thin Solid Films 5197959

Yu X, Ma J, Ji F, Wang Y, Zhang X, Cheng C and Ma H 2005a Appl. Surf. Sci. 239222

Yu X, Ma J, Ji F, Wang Y, Zhang X, Cheng C and Ma H 2005b J. Cryst. Growth 274474 